\title{
Rhabdoid Features in Leiomyosarcoma of Soft Tissue: With Special Reference to Aggressive Behavior
}

\author{
Yumi Oshiro, M.D., Hideki Shiratsuchi, M.D., Yoshinao Oda, M.D., Satoshi Toyoshima, M.D.,
} Masazumi Tsuneyoshi, M.D.

Department of Anatomic Pathology, Graduate School of Medical Science, Kyushu University

The presence of rhabdoid cells has been reported in various types of malignant neoplasms and has been determined to be a predictor of aggressive behavior of neoplasms regardless of tumor histogenesis. One hundred and thirteen cases of leiomyosarcoma, selected from 1800 soft tissue sarcomas, were reviewed on hematoxylin and eosin sections, and immunohistochemical staining when available, and seven cases with rhabdoid features were retrieved. Clinicopathologic differences were analyzed to compare between cases with rhabdoid features and those without rhabdoid features. In the seven cases with rhabdoid features, two were intra-abdominal, and the others arose in external soft tissues including muscle, subcutis, and cutis. Patient age ranged from 33 to 84 years, three were female, and four were male. Tumor size ranged from 3 to $22 \mathrm{~cm}$. Clinical evidence showed no differences from those cases without rhabdoid features. Histologically, one of the abdominal cases was epithelioid leiomyosarcoma. Two of the 7 cases were better subclassified as pleomorphic leiomyosarcoma, in which rhabdoid cells are diffusely scattered. In cases other than those with pleomorphic leiomyosarcomas, foci of anaplastic areas were observed, and collections of rhabdoid cells were present in those areas. Immunohistochemical examination of the cases confirmed myogenic differentiation, and showed rhabdoid cells being positive for vimentin and desmin in the inclusion bodies, and diffusely so for muscle actin in the cytoplasm. After dividing all the cases of leiomyosarcoma by their location, prognostic analysis was performed. Leiomyosarcoma of external

Copyright (C) 2000 by The United States and Canadian Academy of Pathology, Inc.

VOL. 13, NO. 11, P. 1211, 2000 Printed in the U.S.A.

Date of acceptance: June 13, 2000.

This work was supported in part by a Grant-in-Aid for Cancer Research from the Fukuoka Cancer Society, Fukuoka and a Grant-in-Aid for General Scientific Research from the Ministry of Education, Science, Sports and Culture (09470052), Tokyo, Japan.

Address reprint requests to: Masazumi Tsuneyoshi, M.D., Department of Anatomic Pathology, Graduate School of Medical Science, Kyushu University, 3-1-1 Maidashi, Higashi-ku, Fukuoka, 812-8582 Japan; e-mail: masazumi@surgpath.med.kyushu-u.ac.jp; fax: 81-92-642-5968. soft tissue with rhabdoid cells showed a tendency for poorer prognoses than cases without rhabdoid features. On the contrary, retroperitoneal cases did not. This study indicates that rhabdoid features are associated with aggressive biological behavior in leiomyosarcoma of the external soft tissue.

KEY WORDS: Leiomyosarcoma; rhabdoid cells.

Mod Pathol 2000;13(11):1211-1218

Leiomyosarcoma is a relatively rare soft-tissue sarcoma, accounting for between 5 and $10 \%$ of softtissue sarcomas. They can be divided into groups as follows: 1) leiomyosarcoma of retroperitoneum and other intra-abdominal sites; 2) leiomyosarcoma of deep soft tissue, other than at abdominal sites; 3 ) leiomyosarcoma of cutaneous or subcutaneous tissue; 4) leiomyosarcoma of vascular origin. The location is important because it is accurately reflected in the outcome for the patient. Tumor size is also known to be an important prognostic factor. Histological features of leiomyosarcoma, case by case, show a great variety of patterns and are not yet recognized as prognostic factors (1-3).

Malignant rhabdoid tumor of the kidney is a distinctive clinicopathological entity that is recognized as a highly aggressive renal tumor of childhood (4-6). Extrarenal malignant rhabdoid tumors have been proposed to exist at several sites, including soft parts. However, there have been doubts as to the existence of such an entity, because of the lack of clinicopathologic uniformity among the cases (7-23). Furthermore, the presence of rhabdoid cells has been reported in various types of specific malignant neoplasms, either mesenchymal or epithelial (24-37). Despite the degree of differentiation of tumors with a rhabdoid phenotype, these are now recognized as highly aggressive neoplasms. Only a few examples of leiomyosarcomas have been reported to show rhabdoid features in the reviews of malignant rhabdoid tumors of soft tissue $(8,9)$. In the current study, we describe seven cases of leiomyosarcoma with rhabdoid features and show a relationship to aggressive biological behavior, espe- 
cially in cases of leiomyosarcoma arising in an external soft tissue site.

\section{MATERIALS AND METHODS}

One hundred and thirty-three cases of leiomyosarcoma were reviewed, taken from the 1800 cases of soft-tissue sarcoma in the files of the Department of Anatomic Pathology at Kyushu University, Japan. Leiomyosarcomas originating in the perineal region, vessels, or intestinal wall were excluded from this study. Cases containing significant extent of tumor cells with rhabdoid features, despite relatively low total fraction of cells or only focal collections, are recognized as cases with rhabdoid feature. Cases containing only a few rhabdoid-like cells are not included in the cases. Seven cases with rhabdoid features were retrieved from the files. Representative sections from the available cases were selected for immunohistochemistry. The immunoperoxidase staining was done using the streptavidin biotin-peroxidase method (Histofine SAB-PO Kit, Nichirei Co, Tokyo, Japan). The antibodies used shown in Table 1 .

In 91 of these cases, including six with rhabdoid features, follow-up data was available for analysis. The length of survival was tested by Kaplan-Meier analysis with both Gehan-Wilcoxon and Peto logrank tests.

\section{RESULTS}

\section{Clinical Findings}

Clinical data of all 133 cases of leiomyosarcoma were analyzed to compare between cases with rhabdoid features and those without rhabdoid features. The cases of leiomyosarcoma constituted 86 cases in retroperitoneum, mesentery or other intraabdominal sites (defined as retroperitoneal cases), and 47 cases in nonretroperitoneal external soft tissue sites. External soft tissue cases are composed of 34 cases with depth clarified (21 in superficial sites such as subcutis or cutis and 13 in deeper site such as fascia and muscle of extremities) and 13 with unknown depths. Details of the location of external soft tissue were as follows: 22 cases in lower extremities, 8 each in upper extremities, limb girdle, and trunk, and one of the head. Patient age

TABLE 1. Monochronal antibodies used

\begin{tabular}{llll}
\hline & Clone & \multicolumn{1}{c}{ Source } & Dilution \\
\hline Vimentin & V9 & DAKO & $1: 25$ \\
$\alpha$ SMA & 1A4 & SIGMA & $1: 5000$ \\
Muscle actin & HHF35 & Biomeda & $1: 200$ \\
Desmin & D33 & DAKO & $1: 100$ \\
Cytokeratin & CAM5.2 & Becton Dickinson & $1: 20$ \\
\hline
\end{tabular}

SMA, smooth muscle actin. ranged from 11 to 89 years (mean, 57) in all cases, 24 to 84 (mean, 58) in retroperitoneal cases, 11 to 89 (mean, 54) in external soft tissue cases, and showed no significant differences. Male-to-female ratio was 53:78 (unknown, 2), 36:49 in retroperitoneal cases, and 17:29 in external soft tissue cases. Tumor sizes ranged from 5 to $35 \mathrm{~cm}$ (mean, 13.8) in retroperitoneal cases and 1 to 25 (mean, 5.8) in external soft tissue cases including superficial cases (mean, 3.8) and deep external soft tissue cases (mean, 9.2). Significant differences were observed between the tumor sizes of abdominal cases and those of superficial cases $(P<0.001)$, and also between deep external soft tissue cases and superficial cases $(P=$ 0.002557).

Seven cases showed rhabdoid features. A summary of the clinicopathological data of the cases with rhabdoid features is listed in Table 2. In these cases, patient age ranged from 33 to 84 years, three were female, and four were male. Tumor size ranged from 3 to $22 \mathrm{~cm}$. Patient ages and tumor sizes showed no differences between cases with rhabdoid features and those without rhabdoid features, regardless of the tumor site.

\section{Therapy}

The summary of the therapy in patients with rhabdoid features is listed also in Table 2. In patient 1 , with an intra-abdominal mass, the tumor was easily resected from the omentum. The other with an intra-abdominal mass, patient 2 , showed no invasion to the surrounding organs and was treated by excision. Patient 3, with a subcutaneous tumor, underwent excision with a required wide surgical margin. In patient 4 , a subcutaneous tumor was also excised with a wide margin. Patient 5 had an intramuscular tumor that was easily movable and was excised with the required wide surgical margin after preoperative chemotherapy with vincristine, actinomycin-D, and cyclophosphamide. In patient 6 , with a tumor arising in the thigh, pulmonary metastasis was found at presentation and the patient underwent preoperative radiation and chemotherapy with adriamycin, vincristine, and cyclophosphamide, followed by the excision of the tumor arising in the sartorius muscle. In the remaining case, of a tumor arising in the buttocks, the tumor was excised but details are not known.

\section{Histological Findings}

The seven cases with rhabdoid features showed a great variety of histological features compared with leiomyosarcomas without rhabdoid features. Three cases showed well to moderately differentiated leiomyosarcoma, displaying interlacing bundles of elongated spindle cells with abundant eosinophilic 
TABLE 2. List of cases with rhabdoid features

\begin{tabular}{|c|c|c|c|c|c|c|c|}
\hline Patient & Age & Sex & Site & Size $(\mathrm{cm})$ & Therapy & Prognosis & Histologic finding \\
\hline 1 & 55 & $\mathrm{~F}$ & Abdominal cavity & $18 \times 9.5$ & Marginal excision & 85 mo. Alive & Epithelioid leiomyosarcoma \\
\hline 2 & 62 & $\mathrm{~F}$ & Omentum & $13 \times 10$ & Marginal excision & Unknown & Moderately differentiated \\
\hline 3 & 53 & $\mathrm{~F}$ & Thigh, subcutis & $8 \times 6$ & Wide excision & 19 mo. DOD & Moderately differentiated \\
\hline 4 & 76 & M & Buttock, subcutis & $6 \times 5$ & Wide excision & 27 mo. Alive & Pleomorphic, myxoid MFH like area \\
\hline 5 & 33 & M & Thigh muscle & $5 \times 6$ & Wide excision after chemotherapy & 45 mo. DOD & Poorly differentiated \\
\hline 6 & 54 & M & $\begin{array}{l}\text { Thigh muscle } \\
\text { with lung meta. }\end{array}$ & $22 \times 10$ & $\begin{array}{l}\text { Wide excision after radiation and } \\
\text { chemotherapy }\end{array}$ & 9 mo. DOD & Well to moderately differentiated \\
\hline 7 & 84 & M & Buttock & $3 \times 3$ & Excision, unknown detail & 93 mo. Alive & Pleomorphic \\
\hline
\end{tabular}

DOD, death from disease; meta, metastasis.

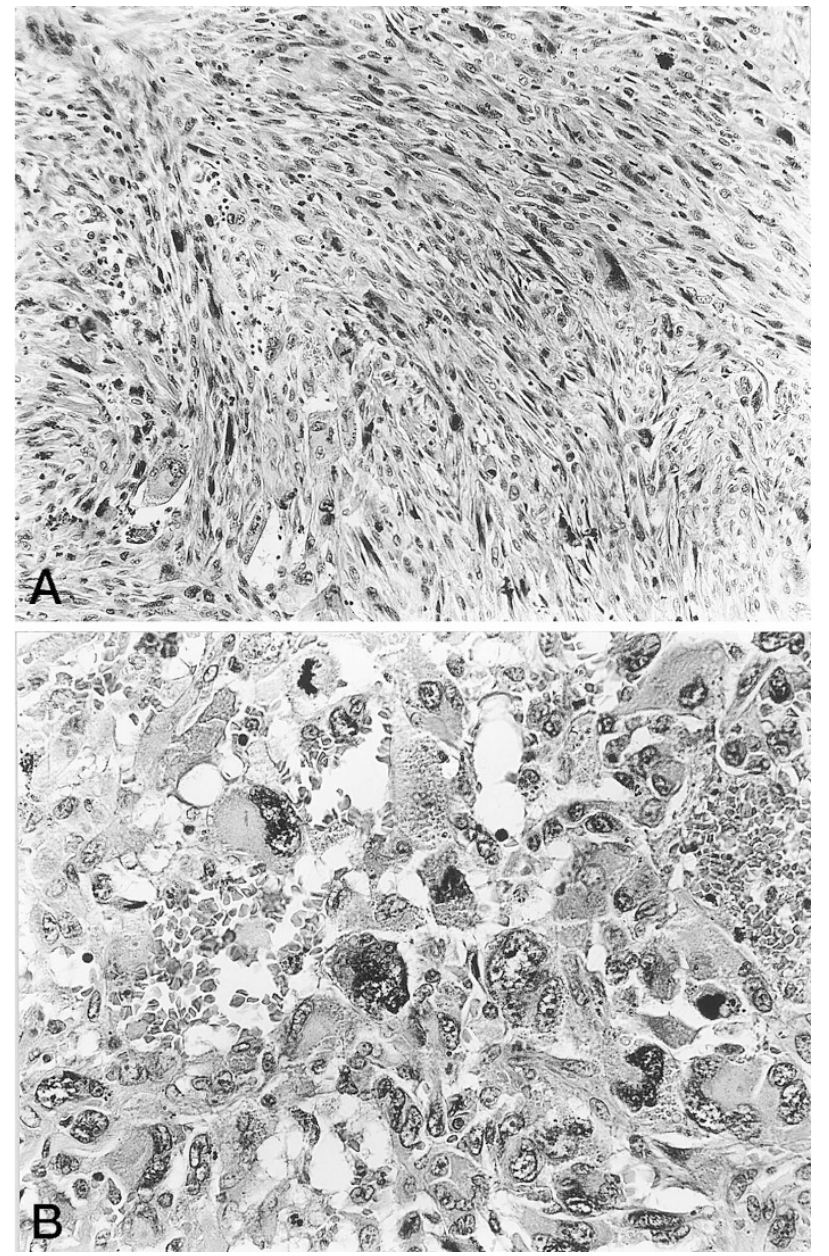

FIGURE 1. Leiomyosarcoma arising in the subcutis of the thigh. Patient died from disease at 19 months (patient 3). A, Well-defined fascicular structure of the tumor cells. B, Anaplastic foci containing large polygonal cells with globular cytoplasmic inclusion (hematoxylin and eosin).

or clear cytoplasm (Fig. 1A, 2A). One of them was a poorly differentiated type consisting of short spindle cells with less identifiable longitudinal striations (Fig. 3A). Those cases revealed anaplastic foci and a collection of poorly differentiated anaplastic cells. The areas contained relatively large polygonal cells that had eccentric nuclei with prominent nucleoli and eosinophilic globular perinuclear inclusion, similar to those seen in malignant rhabdoid tumors (Fig. 1B, 2B, 3B). Another two cases contained numerous anaplastic large cells with highly pleomor-

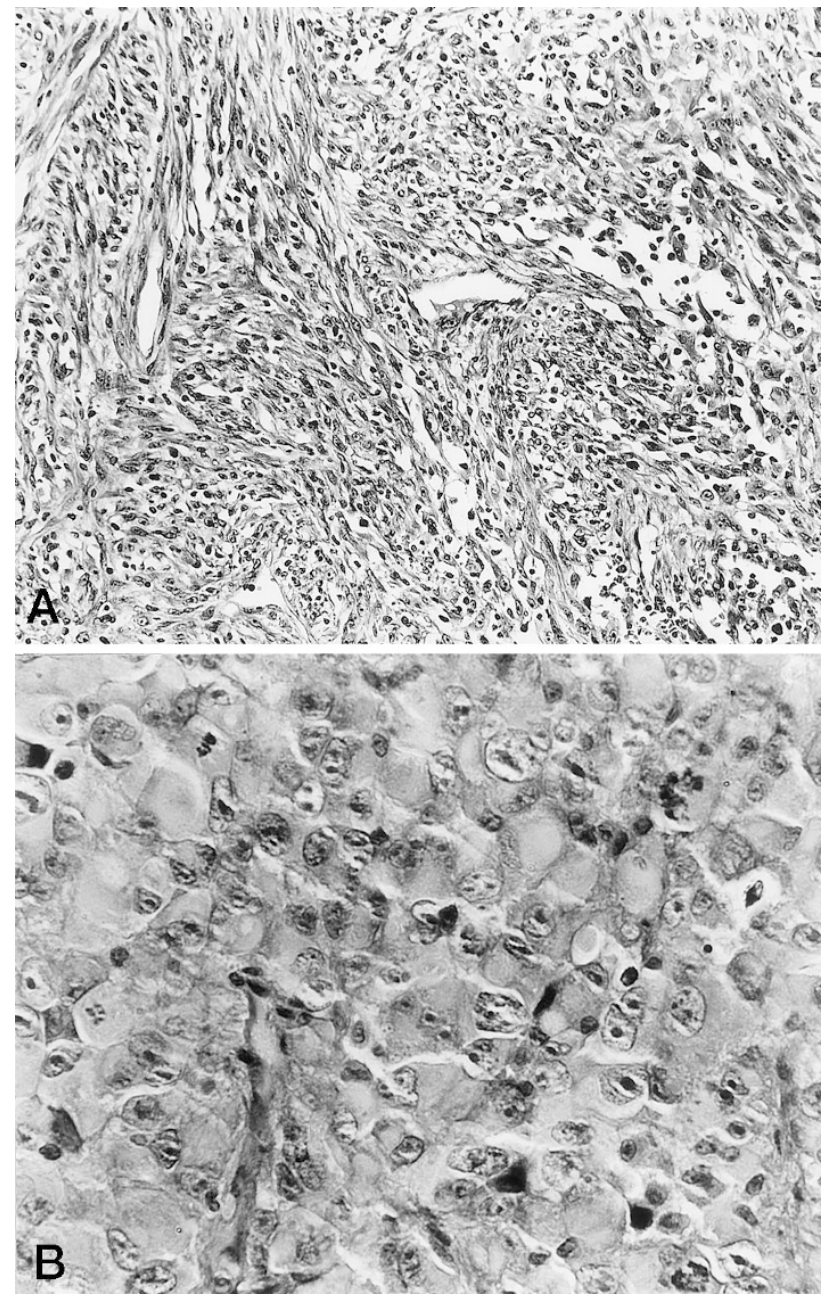

FIGURE 2. Leiomyosarcoma arising in the muscle of the thigh. Patient died from disease at 9 months (patient 6). A, Well-defined fascicular structure of the tumor cells. B, A collection of rhabdoid cells is observed in part (hematoxylin and eosin).

phic nuclei, intimately admixed with a component of spindled cells in the fascicles. Although those two cases superficially resembled pleomorphic malignant fibrous histiocytoma (MFH), a smooth muscle differentiation was documented by immunohistochemistry and Masson trichrome stainings. One of these pleomorphic cases partly showed a nodular configuration with anaplastic tumor cells floating in the myxoid matrix, resembling myxoid malignant fibrous histiocytoma MFH. Those pleomorphic 


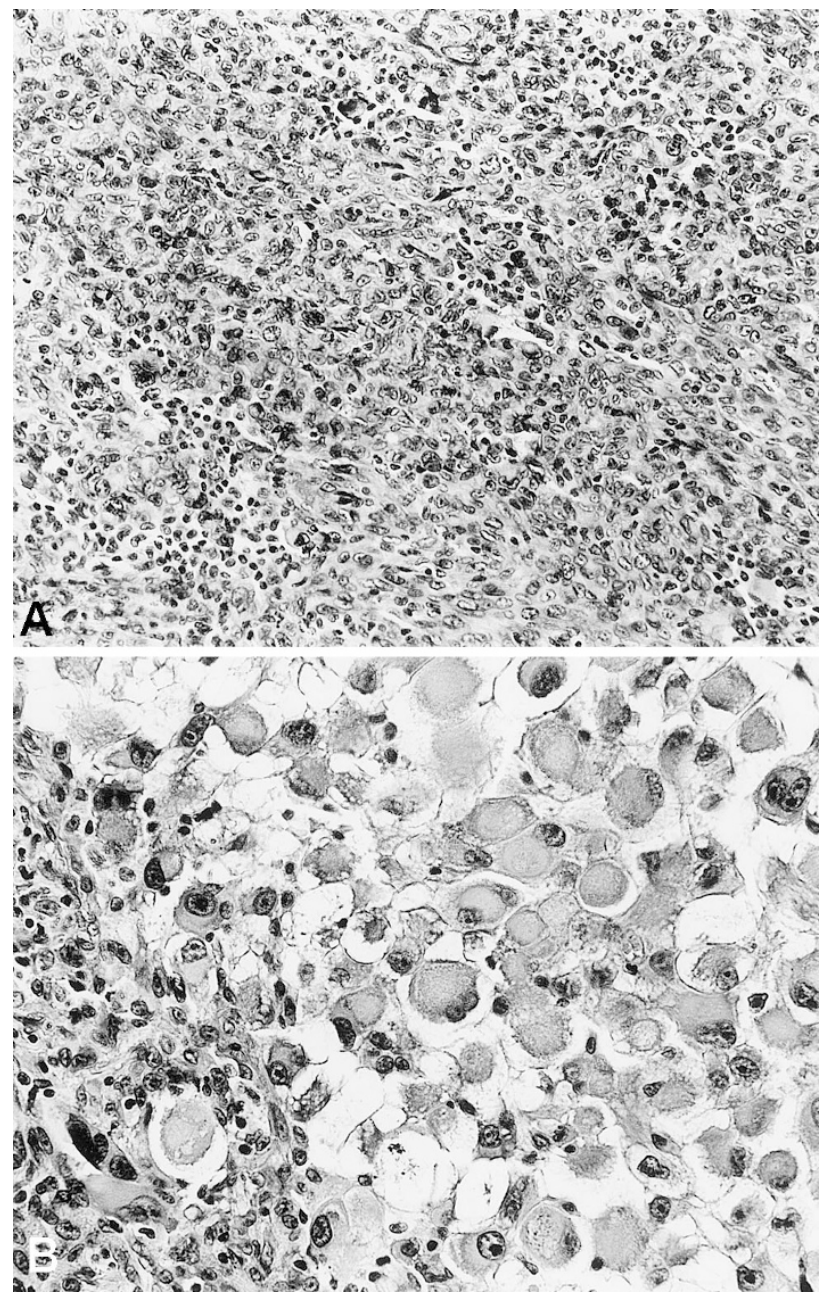

FIGURE 3. Leiomyosarcoma arising in muscle of the thigh. Patient died from disease at 45 months (patient 5). A, Short spindle tumor cells showing no defined fascicular structure. B, Anaplastic foci show aggregates of rhabdoid cells with prominent cytoplasmic inclusion.

cases showed some rhabdoid cells scattering throughout the tumor. One case arising in the abdominal cavity was classified as an epithelioid leiomyosarcoma and collections of rhabdoid cells were focally present (Fig. 4). The foci of rhabdoid cells have an association with hemorrhagic regions. Sometimes multinucleated giant cells with rhabdoid-like inclusion were also present.

\section{Immunohistological Results}

Of the cases with rhabdoid features, six were available for immunohistochemistry (Table 3). All six cases showed positivity for vimentin, HHF35, and $\alpha$-smooth muscle actin. Four cases were positive for desmin. The inclusion bodies in anaplastic cells showing rhabdoid features were positive for vimentin in all five cases, and desmin in four cases with globular fashion (Fig. 5, A-B), whereas cells other than those with a rhabdoid phenotype showed a diffuse positivity in the cytoplasm for desmin and vimentin. Actins showed a diffuse pos-

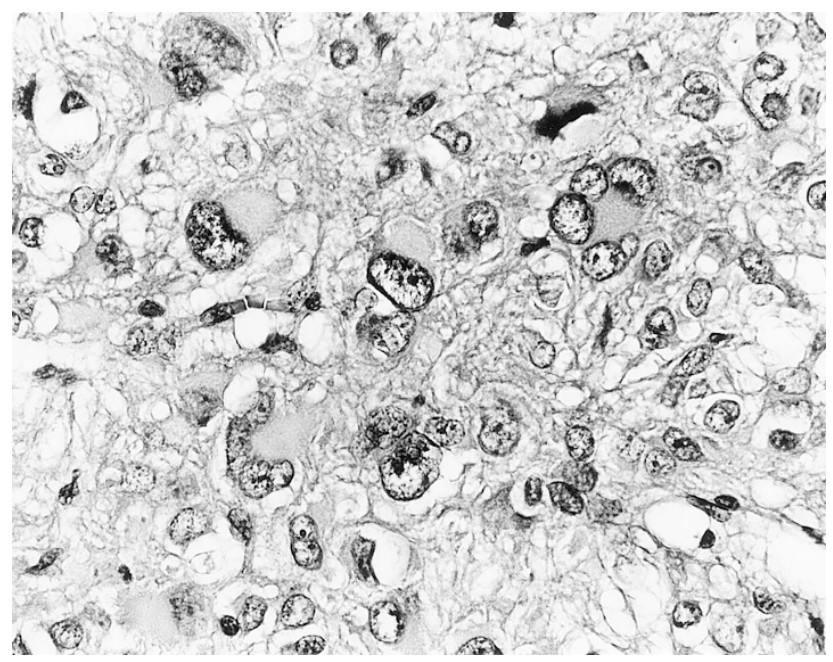

FIGURE 4. Retroperitoneal type of epithelioid leiomyosarcoma. Patient alive at 85 months (patient 1). Anaplastic foci show large sized tumor cells occasionally containing cytoplasmic inclusions.

TABLE 3. Immunohistochemical results

\begin{tabular}{cccccc}
\hline Case & vimentin & $\alpha$-SMA & HHF & desmin & Cam5.2 \\
\hline 1 & + & + & + & ND & - \\
2 & + & + & weekly + & + & - \\
3 & + & + & + & weekly + & - \\
4 & + & + & focally + & - & - \\
5 & + & + & + & + & - \\
6 & + & + & + & + & - \\
7 & ND & ND & ND & ND & ND \\
\hline
\end{tabular}

ND, not done; SMA, smooth muscle actin.

itivity in the cytoplasm but not in globular configurations like intermediate filaments (Fig. 5, C-D). Cytokeratin was negative in all the cases. All cases were also negative for myoglobin.

\section{Prognosis with Statistical Analyses}

Follow-up information was available in 91 cases. The follow-up periods ranged from 4 days to 27 years, 7 months (mean, 4 years, 10 months). The 5 -year survival rate in all the cases was $45 \%$, and the 10 -year rate was $40 \%$. In retroperitoneal cases, the 5 -year survival rate was $32 \%$ and the 10 -year rate was 29, and 68 and 55\%, respectively, in all the external soft tissue cases. Retroperitoneal cases had significantly poorer prognoses than external soft tissue cases $(P=0.0002)$. Tumor size was a prognostic factor in external soft tissue cases $(P=$ 0.0068 ), but not in retroperitoneal cases. There was no prognostic difference with respect to patient age.

Prognostic analyses by rhabdoid features were done after dividing into retroperitoneal and external soft tissue cases. Patients with rhabdoid features had a poorer prognosis than those without rhabdoid features in external soft tissue cases $(P=$ 0.0350 by Peto log-rank test, $P=0.0547$ by GehanWilcoxon test) but not in retroperitoneal cases. 


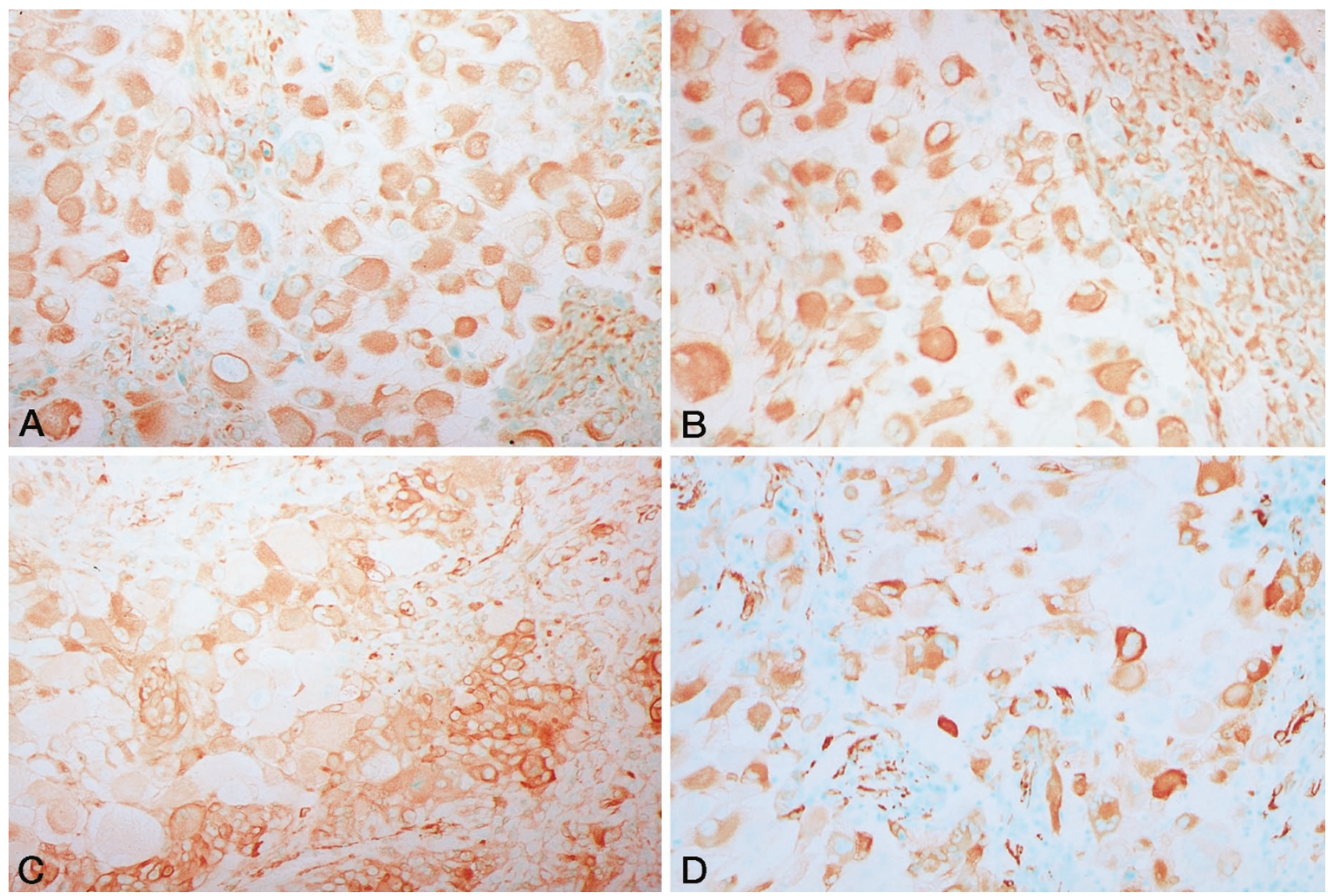

FIGURE 5. Immunohistochemical findings of leiomyosarcoma arising in muscle of the thigh (patient 5). Vimentin (A) and desmin (B) are stained at the cytoplasmic inclusion in the rhabdoid cells, whereas HHF35 (C) and $\alpha$-SMA (D) are diffusely positive in the cytoplasm of the tumor cells. All the antibodies are also strongly positive in the small-sized tumor cells, corroborating leiomyosarcoma, though poorly differentiated.

\section{DISCUSSION}

Rhabdoid cells appear diffusely in malignant rhabdoid tumors. The term malignant rhabdoid tumor was originally used to describe a type of pediatric renal tumor with a clinicopathologic distinction from Wilms' tumors $(1,2)$. Although rare, malignant rhabdoid tumors of the kidney demonstrate particularly aggressive growth and poor prognosis.

There is substantial report of rhabdoid morphology's being observed in a broad spectrum of tumor types, such as malignant tumors reported as extrarenal rhabdoid tumors arising in various extrarenal sites (7-23), and a variety of malignant neoplasms of known histogenesis, including either epithelial or nonepithelial malignant tumors (24-37). Concerning prognosis in cases with rhabdoid morphology, Wick et al. determined that less than $50 \%$ of patients with extrarenal rhabdoid tumors have survived for 5 years without tumor recurrence (9). In cases of extrarenal rhabdoid tumors reported by Parham et al., the 5-year survival rate was about $25 \%$ (7). In addition to those large series, several individual case reports have also demonstrated poor prognosis of the cases. After all, malignant neoplasms with rhabdoid morphology, along with malignant rhabdoid tumor of the kidney, are now recognized as highly aggressive neoplasms.

Some doubts regarding about an entity of "extrarenal rhabdoid tumor" still exist. In a recent study, a reassessment of extrarenal rhabdoid tumors was performed by Leong et al. with the lesions actually representing leiomyosarcoma, carcinomas, epithelioid sarcoma, and desmoplastic small round cell tumors (8). Wick et al., who also suggested that rhabdoid tumors reflect a phenotype of heterogenous derivation, support the retention of the diagnosis of rhabdoid tumor because of an association with aggressive biological behavior (9). Parham et al. reviewed 42 cases of tumors that were initially diagnosed as extrarenal rhabdoid tumors (7). They found that in all but 11 of the 42 cases, rhabdoid tumor cells appeared only as a component of poorly differentiated neoplasms, including histologically defined sarcoma, carcinomas, melanomas, and carcinosarcomas. They held the definition of extrarenal rhabdoid tumors for the 11 cases of primitive sarcoma of unknown histogenesis with rhabdoid features as "true" extrarenal rhabdoid tumors. 
The sequential appearance of rhabdoid cells among primitive neoplasms of undetermined histogenesis through specific malignant neoplasms indicates that the rhabdoid phenotype could be a potential final pathway for the evolution of various neoplasms as they progress to a higher-grade, more aggressive biological state (38).

The presence of rhabdoid cells in soft-tissue neoplasms has been reported in epithelioid sarcoma $(24,35,37)$, synovial sarcoma $(24,26,36)$, extraskeletal myxoid chondrosarcoma (24), malignant mesothelioma $(24,29)$, desmoplastic small round cell tumors $(39,40)$, malignant peripheral nerve sheath tumors (41), and even in rhabdomyosarcoma (42). Wick et al. demonstrated one case of leiomyosarcoma with rhabdoid features, but the details are unclear (9). Leong et al. retrieved a case of gastric leiomyosarcoma from a putative extrarenal malignant rhabdoid tumor (8). Regarding the immunoreactivity for intermediate filaments in the rhabdoid cells, almost all cases were reactive for vimentin, and the majority of the cases were positive for cytokeratin as well. Cytokeratins 8 and 18 were detected in rhabdoid cells in a malignant rhabdoid tumor (unpublished observations). Other intermediate filaments, like desmin, neurofilament, or glialfibrillary acidic protein, have been detected in the few cases reported $(7,12,30)$. Several cases of malignant rhabdoid tumors reported previously have showed desmin positivity, revealing a potential for myogenic differentiation $(6,9,10)$. Except for those cases, leiomyosarcoma with rhabdoid features have not yet been reported.

Recently, new subtypes of leiomyosarcoma, such as inflammatory leiomyosarcoma and leiomyosarcoma with osteoclast-like giant cells, have been proposed $(43,44)$. Leiomyosarcomas with areas simulating myxoid MFH are also reported (45). Pleomorphic leiomyosarcoma have been also been compared with ordinary-type MFH $(46,47,49)$. After this, leiomyosarcoma should be more common in human soft part sarcomas. Leiomyosarcomas are subdivided according to the tumor location, such as leiomyosarcomas of retroperitoneum or mesentery, leiomyosarcoma of deep external soft tissue, leiomyosarcoma arising in cutis and subcutis, and of vascular origin (1-3). Nielsen et al. proposed a different criteria for tumors arising in vulva to distinguish between leiomyomas and leiomyosarcomas (48). The subgrouping is important because of the biological and clinical differences. In the present study, we investigated the prognostic significance of the presence of rhabdoid features after dividing leiomyosarcomas into the subgroups. The cases of retroperitoneal leiomyosarcoma showed no correlation between the rhabdoid features and prognosis, probably because of the high aggressiveness of those cases, in which the 5-year survival was only $32 \%$. On the other hand, in external soft tissue, leiomyosarcomas with rhabdoid features tended to have poorer prognosis than those without rhabdoid features. However, because of the limited data, many more cases need to be analyzed before this can be confirmed.

Rhabdoid cells should be distinguished from rhabdomyoblasts because the tumors presented in this study show myogenic differentiation. Rhabdomyoblasts in rhabdomyosarcomas display another type of cytoplasmic globular arrangement that is deeply eosinophilic, compared with the inclusions in rhabdoid cells being more homogeneous, better circumscribed, and not so prominently eosinophilic (42). Furthermore, pleomorphic rhabdomyosarcomas lack a consistent growth pattern and form poorly defined aggregates in most tumors, compared with leiomyosarcomas, which show intersecting fascicles, and also show distinctive strap-like tumor cells (50). Myoglobin is positive only in rhabdomyosarcomas.

In conclusion, we found seven cases of leiomyosarcoma with rhabdoid features among 133 leiomyosarcomas, and these specific cases showed a tendency for poor prognoses. Rhabdoid features should be considered as being a predictor of poor prognosis for leiomyosarcomas, as well as for other neoplasms, as has been reported previously.

Acknowledgments: The authors sincerely thank Dr. Iwabuchi, Kitazato University, and Dr. A Yoshida, Kagoshima University for providing informations of patients. We also thank Mr. Kerry Greer for proofing the English.

\section{REFERENCES}

1. Fields JP, Helwig EB. Leiomyosarcoma of the skin and subcutaneous tissue. Cancer 1981;47:156-69.

2. Wile AG, Evans HL, Romsdahl MM. Leiomyosarcoma of soft tissue. A clinicopathologic study. Cancer 1981;48:1022-32.

3. Hashimoto H, Daimaru Y, Tsuneyoshi M, Munetomo E. Leiomyosarcoma of the external soft tissue. A clinicopathologic, immunohistochemical, and electron microscopic study. Cancer 1986;57:2077-88.

4. Beckwith JB, Palmer NF. Histopathology and prognosis of Wilms' tumor: results from the first National Wilms' Tumor Study. Cancer 1978;41:1937-48.

5. Haas JE, Palmer NF, Weinberg AG, Beckwith JB. Ultrastructure of malignant rhabdoid tumor of the kidney: a distinct renal tumor of children. Hum Pathol 1981;12:646-57.

6. Kodet R, Newton WA, Sachs N, Hamoudi AB, Raney RB, Asmar L, Gehan EA. Rhabdoid tumors of soft tissues: a clinicopathologic study of 26 cases enrolled on the intergroup rhabdomyosarcoma study. Hum Pathol 1991;22:67484.

7. Parham DM, Weeks DA, Beckwith JB. The clinicopathologic spectrum of putative extrarenal rhabdoid tumors: an analysis of 42 cases studied with immunohistochemistry or electron microscopy. Am J Surg Pathol 1994;18:1010-29. 
8. Leong FJWM, Leong ASY. Malignant rhabdoid tumor in adults-Heterogenous tumors with a unique morphological phenotype. Pathol Res Pract 1996;192:796-807.

9. Wick MR, Ritter JH, Dehner LP. Malignant rhabdoid tumors: a clinicopathologic review and conceptual discussion. Semin Diagn Pathol 1995;12:233-48.

10. Gururangan S, Bowman LC, Parham DM, Wiliams JA, Rao B, Pratt CB, Douglass EC. Primary extracranial rhabdoid tumors. Clinicopathologic features and response to ifosfamide. Cancer 1993;71:2653-9.

11. Tsokos M, Kouraklis G, Chandra RS, Bhagavn BS, Triche TJ. Malignant rhabdoid tumor of the kindey and soft tissues. Evidence for a diverse morphological and immunocytochemical phenotype. Arch Pathol Lab Med 1989;113:115-20.

12. Kent AL, Mahoney DH, Gresik MV, Steuber CP, Fernabach DJ. Malignant rhabdoid tumor of the extremity. Cancer 1987; 60:1056-9.

13. Frierson HF, Mills SE, Innes DJ. Malignant rhabdoid tumor of the pelvis. Cancer 1985;55:1963-7.

14. Macus VA, Viloria J, Owen D, Tsao MS. Malignant rhabdoid tumor of the colon. Dis Colon Rectum 1996;39:1322-6.

15. Hunt SJ, Anderson WD. Malignant rhabdoid tumor of the liver. A distinct clinicopathologic entity. Am J Clin Pathol 1990;94:645-8.

16. Harris M, Eyden BP, Joglekar VM. Rhabdoid tumor of the bladder. A histological, ultrastructural and immunohistochemical study. Histopathology 1987;11:1083-92.

17. Walford N, Deferrai R, Slater RM, Delemarre JF, Dingemans $\mathrm{KP}$, Van den Bergh Weerman MA, et al. Intra-orbital rhabdoid tumor following bilateral retinoblastoma. Histopathology 1992;20:170-3.

18. Matias C, Nunens JFM, Vicente LF, Almeida MO. Primary malignant rhabdoid tumor of the vulva. Histopathology 1990;17:576-8.

19. Perrone T, Swanson PE Twiggs L Ulbright TM Dehner LP. Malignant rhabdoid tumor of the vulva. Is distinction from epithelioid sarcoma passible? A pathologic and immunohistochemical study. Am J Surg Pathol 1989;13:848-58.

20. Cattani MG, Viale G, Santini D, Martinelli GN. Malignant rhabdoid tumor of the uterus. An immunohistochemical and ultrastructural study. Virchows Arch A Pathol Anat Histopathol 1992;420:459-62.

21. Satoh H, Goishi J, Sogabe T, Uozumi T Kiya K Migita K. Primary malignant rhabdoid tumor of the central nervous system. Case report and review of the literature. Surg Neurol 1993;40:429-34.

22. Jakate SM, Marsden HB, Ingram L, Primary rhabdoid tumor of the brain. Virchows Arch A Pathol Anat Histopathol 1988; 412:393-7.

23. Biggs PJ, Garen PD, Powers JM, Garvin AJ. Malignant rhabdoid tumor of the central nervous system. Hum Pathol 1987; 18:332-7.

24. Tsuneyoshi M, Daimaru Y, Hashimoto H, Enjoji M. The existence of rhabdoid cells in specified soft tissue sarcomas. Histopathological, ultrastructural, and immunohistochemical evidence. Virchows Arch A Pathol Anat Histopathol 1987; 411:509-14.

25. Ueyama T, Nagai E, Yao T, Tsuneyoshi M. Vimentin-positive gastric carcinomas with rhabdoid features. A clinicopathologic and immunohistochemical study. Am J Surg Pathol 1993;17:813-9.

26. Oda Y, Hashimoto H, Tsuneyoshi M, Takeshita S. Survival in synovial sarcoma: a multivariate study of prognostic factors with special emphasis on the comparison between early death and long-term survival. Am J Surg Pathol 1993;17:3544.

27. McCluggage WG, Date A, Bharucha H, Toner PG. Endometrial stromal sarcoma with sex cord-like areas and focal rhabdoid differentiation. Histopathol 1996;29:369-74.
28. Utsunomiya T, Yao T, Masuda K, Tsuneyoshi M. Vimentinpositive adenocarcinomas of the stomach: co-expression of vimentin and cytokeratin. Histopathol 1996;29:507-16.

29. Matsukuma S, Aida S, Hata Y, Sugiura Y, Tamai S. Localized malignant peritoneal mesothelioma containing rhabdoid cells. Pathol Int 1996;46:389-91.

30. Cavazza A, Colby T, Tsokos M, Rush W, Travis WD. Lung tumors with a rhabdoid phenotype. Am J Clin Pathol 1996; 105:182-8.

31. Nishhiara K, Katsumoto F, Kurokawa Y, Toyoshima S, Takeda S, Abe R. Anaplastic carcinoma showing rhabdoid features combined with mucinous cystadenocarcinoma of the pancreas. Arch Pathol Lab Med 1997;121:1104-7.

32. Chetty R, Bhana B, Batitang S, Govender D. Lung carcinomas composed of rhabdoid cells. Eur J Surg Oncol 1997;23:432-4.

33. Perry A, Scheithauer BW, Stafford SL, Abell-Aleff PC, Meyer FB. "Rhabdoid" meningioma: an aggressive variant. Am J Surg Pathol 1998;22:1482-90.

34. Kepes JJ, Moral LA, Wilkinson SB, Abdullah A, Llena JF. Rhabdoid transformation of tumor cells in meningiomas: a histologica indication of increased proliferative activity. Report of four cases. Am J Surg Pathol 1998;22:231-8.

35. Miettinen M, Fanburg-smith JC, Virolainen M, Shmookler BM, Fetsch JF. Epithelioid sarcoma: an immunohistochemical analysis of 112 classical and variant cases and a discussion of the differential diagnosis. Hum Pathol 1999;30:93442.

36. Machen SK, Easley KA, Goldblum JR. Synovial sarcoma of the extremities: a clinicopathologic study of 34 cases, including semi-quantitative analysis of spindled, epithelial, and poorly differentiated areas. Am J Surg Pathol 1999;23:26875.

37. Guillou L, Wadden C, Coindre JM, Krausz T, Fletcher CDM. "Proximal-type" epithelioid sarcoma, a distinctive aggressive neoplasm showing Rhabdoid features. Clinicopathologic, immunohistochemical, and ultrastructural study of a series. Am J Surg Pathol 1997;21:130-46.

38. Brooks JJ. The significance of double phenotypic patterns and markers in human sarcomas. A new model of mesenchymal differentiation. Am J Pathol 1986;125:113-23.

39. Gerald WL, Miller HK, Battifora H, Miettinen M, Silva EG, Rosai J. Intraabdominal desmoplastic small round-cell tumor. Report of 19 cases of a distinctive type of high-grade polyphenotypic malignancy affecting young individuals. Am J Surg Pathol 1991;15:499-513.

40. Parkash V, Gerald WL, Parma A, Miettinen M, Rosai J. Desmoplastic small round cell tumor of the pleura. Am J Surg Pathol 1995;19:659-65.

41. Laskin WB, Weiss SW, Bratthauer GL. Epithelioid variant of malignant peripheral nerve sheath tumor (malignant epithelioid schwannoma). Am J Surg Pathol 1991;15:1136-45.

42. Kodet R, Newton WA Jr, Hamoudi AB, Asmar L. Rhabdomyosarcomas with intermediate filament inclusions and features of rhabdoid tumors: light microscopic and immunohistochemical study. Am J Surg Pathol 1991;15:257-67.

43. Mentzel T, Calonje E, Fletcher CDM. Leiomyosarcoma with prominent osteoclast-like giant cells. Analysis of eight cases closely mimicking the so-called giant cell variant of malignant fibrous histiocytoma. Am J Surg Pathol 1994;18:258-65.

44. Merchant W, Calonje E, Fletcher CDM. Inflammatory leiomyosarcoma: a morphological subgroup within the heterogeneous family of so-called inflammatory malignant fibrous histiocytoma. Histopathology 1995;27:525-32.

45. Rubin BP, Fletcher CDM. Myxoid leiomyosarcoma of soft tissue, an underrecognized variant [abstract]. Mod Pathol 1999;12:15A. 
46. Schurch W, Begin LR, Seemayer TA, Lagace R, Boivin JC, Lamoureux C, Bluteau P, Piche J, Gabbiani G. Pleomorphic soft tissue myogenic sarcomas of adulthood. A reappraisal in the mid-1990s. Am J Surg Pathol 1996;20:131-47.

47. Yamamoto I, Oshiro Y, Fukuda T, Tsuneyoshi M. Pleomorphic leiomyosarcoma of the soft parts: a reassessment by histology and immunohistochemistry of pleomorphic soft tissue sarcomas. Oncol Rep 1999;6:533-7.

48. Nielsen GP, Rosenberg AE, Koerner FC, Young RH, Scully RE. Smooth-muscle tumors of the vulva. A clinicopathological study of 25 cases and review of the literature. Am J Surg Pathol 1996;20:779-93.

49. Fletcher CDM. Pleomorphic malignant fibrous histiocytoma: fact or fiction? A critical reappraisal based on 159 tumors diagnosed as pleomorphic sarcoma. Am J Surg Pathol 1992; $16: 213-28$.

50. Gaffney EF, Dervan PA, Fletcher CDM. Pleomorphic rhabdomyosarcoma in adulthood. Analysis of 11 cases with definition of diagnostic criteria. Am J Surg Pathol 1993;17: 601-9. 